(2) Open Access Full Text Article

ORIGINAL RESEARCH

\title{
Association of Acne with Face Mask in Healthcare Workers Amidst the COVID-19 Outbreak in Karachi, Pakistan
}

\author{
Sadia Yaqoob (D) \\ Amna Saleem (iD) \\ Furqan Ahmad Jarullah' \\ Areeba Asif ${ }^{\prime}$ \\ Mohammad Yasir Essar ${ }^{2}$ \\ Shaista Emad ${ }^{3}$ \\ 'Department of Medicine, Jinnah Medical \\ and Dental College, Karachi, Pakistan; \\ ${ }^{2}$ Department of Dentistry, Kabul \\ University of Medical Sciences, Kabul, \\ Afghanistan; ${ }^{3}$ Department of \\ Biochemistry, Sohail University, Karachi, \\ Pakistan
}

Background: In the wake of coronavirus (COVID-19) global alert, people have begun to practice safety measures in order to reduce the exposure to life-threatening disease. The largest at risk population is undoubtedly the frontline healthcare workers (HCWs) who are using personal protective equipment (PPE), essentially face masks, to battle against this deadly virus. This study was conducted with the prime intention to reveal an association between face mask and acne and measure the prevalence of acne amongst HCWs amidst COVID-19 outbreak in Karachi. Furthermore, this study aimed to identify the type of mask generating acne, locate the common sites, assess the severity and establish an association of mask use with the skin type.

Methods: This cross-sectional study was carried out at Medicare Cardiac and General Hospital, Jinnah Medical College Hospital, Jinnah Postgraduate Medical Centre and Jamal Noor Hospital located in Karachi, Pakistan. A total of 348 HCWs were interviewed, of which only 193 met the inclusion criteria. All information was recorded on a predesigned proforma and analyzed using SPSS 25.0.

Results: Among 193 participants, acne was prevalent in 103 (53.4\%) participants with maximum cases reported in female HCWs, and in doctors $(\mathrm{p}<0.05)$. Out of $73 \mathrm{HCWs}$ using N-95 masks, 46 (44.7\%) developed acne, with a p-value of 0.036. Skin type and past history of acne also yielded statistically significant results. Among all the skin types, HCWs with oily skin $(64,62.1 \%)$ were prone to face resurgence of acne or new-onset acne. The most common sites of eruption of acne were along the cheeks $(45.1 \%)$ followed by the nose $(40.9 \%)$. Majority of the population suffered from mild acne. Moderate and severe acne eruption was particularly observed in those wearing N-95 and surgical masks.

Conclusion: The use of face masks is associated with high rates of acne eruption. Disseminating the guidelines and indications of World Health Organization (WHO) regarding proper use of mask, encouraging awareness among HCWs and following proper doffing and donning protocol as endorsed by Centers for Disease Control and Prevention (CDC) will possibly minimize the adverse reactions.

Keywords: acne, facemask, healthcare worker, COVID-19

\section{Plain Language Summary}

What we already know:

- Healthcare workers use facemask as precautionary measure following COVID-19.

- Frequent use of facemask caused acne in many HCW.
Correspondence: Mohammad Yasir University of Medical Sciences, Kabul, 100I, Afghanistan

Email yasir.essar@gmail.com 
What this article adds:

- Prevalence of acne amongst healthcare workers.

- Type of mask that increases susceptibility to acne.

- This article also explains the most common site of acne, assesses the grading, and develops an association between skin types with acne eruption in HCW following COVID-19.

\section{Introduction}

In the awake of coronavirus (COVID-19) global alert, people have begun to practice safety measures in order to reduce the exposure to life-threatening disease. The largest at risk population is undoubtedly the healthcare workers (HCWs) who are in close contact with patients of various diseases, inclusive of those suffering from coronavirus, thus making it quite challenging. ${ }^{1}$ Healthcare professionals are using personal protective equipment (PPE) to tackle this virus on the frontline for hours on a daily basis. ${ }^{2,3}$ One PPE in particular that has gained maximum popularity is the face mask.

A face mask is a piece of covering that generally aims to cover the oral and nasal apertures, while being hooked onto the ears. Three types of face mask are most commonly used in Pakistan, namely: cloth masks, surgical masks and N-95 respirators. It is compulsory for healthcare workers (HCWs) attending to patients with COVID-19 to use PPE, which consequently makes them susceptible to adverse cutaneous reactions, ${ }^{2}$ including acne, itch, rash and, pressure injuries. ${ }^{4}$ One of the common tribulations seen is the outbreak of acne. Friction from skin rubbing up against the mask fabric combined with sweat serves as the best possible explanation for mask-induced acne flare. Irritative symptoms are likely caused by chemicals such as formaldehyde, a component of both N-95 and surgical masks. ${ }^{5,6}$

Acne is the third most prevalent skin dermatoses, characterized by the blockage and/or inflammation of pilosebaceous units and clinically manifesting as whiteheads, blackheads, or pimples. $^{7,8}$ Maskne occurs in people who have a history of acne vulgaris as well as those who have never had acne. ${ }^{9}$ According to one study, $59.6 \%$ of people who wear masks on a regular basis have acne breakouts. ${ }^{10}$ Owing to prolonged use of facemasks, maskne is well-recognized in healthcare workers as compared to the general population. ${ }^{11}$ A study showed that about two dozen healthcare professionals were diagnosed with acne over a period of less than 3 weeks. ${ }^{12}$ Multiple studies have shown the presence of acne on the face. ${ }^{13,14}$ A Chinese study reported a prevalence of $97 \%$ of skin damage related to PPE use among healthcare personnel, with nasal bridge being affected as much as $83.1 \%$ of the time. ${ }^{15}$
Since the COVID-19 outbreak, there has been an increase in the number of patients with acne who require treatment. ${ }^{16}$ Surprisingly, there has been a paradigm shift in the treatment of acne. Isotretinoin, an oral medication primarily used to treat severe acne, is thought to increase coronavirus invasion of the nasal mucosa due to its drying effect on the mucous membranes. ${ }^{17}$ However, there is mounting evidence that supports the use of this drug. It protects against COVID-19 by downregulation of ACE2 receptors, reducing coronavirus entry into susceptible cells. ${ }^{18}$ In light of this evidence, the use of isotretinoin for acne treatment during COVID-era remains debatable.

This study was conducted with the prime intention of establishing an association between face mask and acne and to measure the prevalence of acne amongst healthcare workers. Since fewer studies have been concentrated around this thought, we also aimed to determine which mask type resulted in acne flare-up and which skin type was more susceptible to acne. Furthermore, distribution of acne might also help us conclude our findings effectively.

\section{Methods}

Out of 348 healthcare workers, 193 were included in this cross-sectional study. The study was carried out between 17 September and 17 October 2020 in three hospital settings, namely, Medicare Cardiac and General Hospital, Jinnah Medical College Hospital, Jinnah Postgraduate Medical Centre and Jamal Noor Hospital located in Karachi, Pakistan. The study was conducted in accordance with the Declaration of Helsinki and ethical approval was obtained from Jinnah Medical and Dental College's Ethical Review Committee, and informed consent was taken from all participants (00052/20).

Data was obtained from healthcare professionals including doctors, nurses, pharmacists, technicians and other hospital staff. Individuals aged between 18 and 46 years and those wearing masks were included in the study. We excluded those with (a) facial dermatoses other than acne, (b) known allergies and (c) comorbidities likely to provoke acne to avoid confounders.

A self-structured questionnaire included basic demographic data, details of use of different types of protective measures and acne-related questions. Healthcare workers were interviewed about the following:

- Demographics, which included age, gender, occupation and affiliated healthcare institution. 
- Details of protective measures, which included type of mask used, duration of the use of mask and frequency of doffing mask daily.

- Acne-related questions, which included skin type, previous history of acne, family history of acne, and use of comedogenic skin care products, site of acne and severity of acne. Severity was assessed using the global acne grading system (GAGS). ${ }^{19}$ Each type of lesion is assigned a value depending on severity: no lesions $=0$, comedones $=1$, papules $=2$, pustules $=3$ and nodules $=4$. The score for each site is calculated by obtaining a product of factor and grade $(0-4)$. The factor for each site is listed as ' 2 ' for forehead, right and left cheeks, ' 1 ' for nose and chin, and ' 3 ' for chest and upper back. A score of 1-18 was considered mild; 1930 , moderate; $31-38$, severe; and $>39$, very severe.

Data was analyzed using SPSS 25.0. Descriptive data was summarized with mean, SD and, percentage values. An independent two sample $t$-test was run to compare the means of age amongst the acne positive and negative HCWs. The chi-squared test was done to examine the association between the categorical variables and the two subject groups. A p-value of $<0.05$ was considered to be a limit value for significance.

\section{Results}

The mean age of 193 participants was $27.50 \pm 6.10$ (18-46) years old. The socio-demographic characteristics of HCWs and data pertaining to mask usage and acne are summarized in Table 1.

There were 71 (36.8\%) males and 122 (63.2\%) females. Among these, 114 (59.1\%) were doctors, 46 $(23.8 \%)$ were nurses, $2(1.0 \%)$ were pharmacists, 2 $(1.0 \%)$ were technicians and the remaining $29(15.0 \%)$ constituted other hospital staff.

Acne was prevalent in $103(53.4 \%)$ participants, with maximum cases reported in female HCWs, and in doctors $(\mathrm{p}<0.05)$. Healthcare and other frontline warriors are prone to maskne, a type of acne mechanica, because of prolonged use of tight-fitting respirators. Of all the mask types, results were only significant for N-95 masks $(\mathrm{p}=0.036)$. Out of $73 \mathrm{HCWs}$ using N-95 masks, 46 (44.7\%) developed acne. There was no statistically significant difference across the various sub-groups of duration of mask and frequency of doffing mask daily.

Majority of the study subjects had oily skin (106, $54.9 \%$ ), followed by $61(31.6 \%)$ with combination skin and $26(13.5 \%)$ with dry skin. Among all the skin types, $64(62.1 \%)$ HCWs with oily skin were prone to face resurgence of acne or new-onset acne. There were 59 $(57.3 \%)$ individuals who experienced new onset acne because of the face mask. Family history of acne and comedogenic product usage were not significantly correlated with outbreak of acne after mask use $(\mathrm{p}>0.05)$. Figure 1 demonstrates the distribution of acne. The most common sites of eruption of acne are along the cheeks $(45.1 \%)$, followed by nose $(40.9 \%)$, chin $(31.6 \%)$, forehead $(26.9 \%)$, chest and upper back $(8.3 \%)$. Figure 2 shows the severity of acne according to mask type. Majority of the population suffered from mild acne, with a higher number of cases reported in cloth mask wearers (66.7\%), followed by N-95 mask (58.9\%), and surgical mask (51.6\%) users. Moderate and severe acne eruption were particularly observed in those wearing N-95 and surgical masks.

\section{Discussion}

Since the outbreak of coronavirus, health care professionals have functioned actively over time to facilitate the adequate care to the patients. ${ }^{20}$ While the protective measure has its own advantages, unfortunately using them for an extended time duration has proved to cause various dermatosis including contact dermatitis, seborrheic dermatitis and acne. ${ }^{21}$ The mainstay of this study is to specifically evaluate the correlation between face mask and acne in health care workers of Karachi.

The prevalence of acne in our study after the use of mask was $53.4 \%$ in contrast with $59.6 \%$ reported by Chris C.I $\mathrm{Foo}^{22}$ and $56 \%$ stated by P. K. Purushothaman. ${ }^{23}$ Moreover, prevalence of acne was highest amongst the doctors, which corroborates the findings of a study conducted by Lamees Mahmood Malik. ${ }^{20}$

Amongst all types of mask, healthcare workers using N-95 developed significant acne $(\mathrm{p}<0.036)$ while surgical and cloth mask did not yield a notable contribution in its development. Similar results were obtained by Munise Daye as well as Foo et al, who further support the relation by reporting that $1 / 3$ of health care workers applying N-95 encountered acne in his study. ${ }^{11}$ Local pressure on the skin as a consequence of close-fitting mask may lead to the obstruction of pilosebaceous duct resulting in either the emergence or exacerbation of acne. ${ }^{20}$ According to the analysis in our study, there was no significant difference in acne with the frequency or duration of the mask worn per day. This 
Table I Characteristics of Patients with and without Acne

\begin{tabular}{|c|c|c|c|c|}
\hline Variable & Total $(\mathrm{N}=193)$ & Acne Positive $(n=103)$ & Acne Negative $(n=90)$ & p-value \\
\hline Age, years (mean $\pm S D$ ) & $27.50 \pm 6.10$ & $26.24 \pm 4.28$ & $28.94 \pm 7.44$ & $0.002 *$ \\
\hline $\begin{array}{l}\text { Gender }(\%) \\
\text { Male } \\
\text { Female }\end{array}$ & $\begin{array}{l}71(36.8) \\
122(63.2)\end{array}$ & $\begin{array}{l}31(30.1) \\
72(69.9)\end{array}$ & $\begin{array}{l}40(44.4) \\
50(55.6)\end{array}$ & $0.039 *$ \\
\hline $\begin{array}{l}\text { Occupation (\%) } \\
\text { Doctor } \\
\text { Nurses } \\
\text { Technician } \\
\text { Pharmacist } \\
\text { Others }\end{array}$ & $\begin{array}{l}114(59.1) \\
46(23.8) \\
2(1.0) \\
2(1.0) \\
29(15.0)\end{array}$ & $\begin{array}{l}71(68.9) \\
16(15.5) \\
1(1.0) \\
2(1.9) \\
13(12.6)\end{array}$ & $\begin{array}{l}43(47.8) \\
30(33.3) \\
1(1.1) \\
0(0.0) \\
16(17.8)\end{array}$ & $0.013^{*}$ \\
\hline $\begin{array}{l}\text { Mask type (\%) } \\
\text { N-95 } \\
\text { Surgical } \\
\text { Cloth }\end{array}$ & $\begin{array}{l}73(37.8) \\
186(96.4) \\
3(1.6)\end{array}$ & $\begin{array}{l}46(44.7) \\
100(97.1) \\
2(1.9)\end{array}$ & $\begin{array}{l}27(30.0) \\
86(95.6) \\
I(I . I)\end{array}$ & $\begin{array}{l}0.036^{*} \\
0.570 \\
0.642\end{array}$ \\
\hline $\begin{array}{l}\text { Duration of mask }(\%) \\
<4 \text { hours } \\
4-8 \text { hours } \\
>8 \text { hours }\end{array}$ & $\begin{array}{l}5(2.6) \\
104(53.9) \\
84(43.5)\end{array}$ & $\begin{array}{l}2(1.9) \\
58(56.3) \\
43(41.7)\end{array}$ & $\begin{array}{l}3(3.3) \\
46(5 I . I) \\
4 I(45.6)\end{array}$ & 0.684 \\
\hline $\begin{array}{l}\text { Frequency of changing mask daily (\%) } \\
\text { None } \\
\text { Once } \\
\text { Twice } \\
\text { More than twice }\end{array}$ & $\begin{array}{l}63(32.6) \\
96(49.7) \\
31(16.1) \\
3(1.6)\end{array}$ & $\begin{array}{l}38(36.9) \\
51949.5) \\
13(12.6) \\
1(1.0)\end{array}$ & $\begin{array}{l}25(27.8) \\
45(50.0) \\
18(20.0) \\
2(2.2)\end{array}$ & 0.343 \\
\hline $\begin{array}{l}\text { Skin type (\%) } \\
\text { Oily } \\
\text { Dry } \\
\text { Combination }\end{array}$ & $\begin{array}{l}106(54.9) \\
26(13.5) \\
61(31.6)\end{array}$ & $\begin{array}{l}64(62.1) \\
7(6.8) \\
32(31.1)\end{array}$ & $\begin{array}{l}42(46.7) \\
19(21.1) \\
29(32.2)\end{array}$ & $0.009 *$ \\
\hline $\begin{array}{l}\text { Use of comedogenic products (\%) } \\
\text { Yes } \\
\text { No }\end{array}$ & $\begin{array}{l}135(69.9) \\
58(30.1)\end{array}$ & $\begin{array}{l}80(71.4) \\
32(28.6)\end{array}$ & $\begin{array}{l}55(67.9) \\
26(32.1)\end{array}$ & 0.598 \\
\hline $\begin{array}{l}\text { Past history of acne (\%) } \\
\text { Yes } \\
\text { No }\end{array}$ & $\begin{array}{l}56(29.0) \\
137(71.0)\end{array}$ & $\begin{array}{l}44(42.7) \\
59(57.3)\end{array}$ & $\begin{array}{l}12(13.3) \\
78(86.7)\end{array}$ & $0.000 *$ \\
\hline $\begin{array}{l}\text { Family history of acne (\%) } \\
\text { Yes } \\
\text { No }\end{array}$ & $\begin{array}{l}49(25.4) \\
144(74.6)\end{array}$ & $\begin{array}{l}30(29.1) \\
73(70.9)\end{array}$ & $\begin{array}{l}19(21.1) \\
7 \mid(78.9)\end{array}$ & 0.202 \\
\hline
\end{tabular}

Note: Significant $\mathrm{p}$-value $*_{\mathrm{p}} \leq 0.05$

is contradictory with the literature which suggests prolonged exposure time as a significant risk factor for acne. ${ }^{15}$

Our study revealed that cheeks were the most frequent site involved in eruption of acne, followed by nose and chin. This is conflicting with what M. Singh and JiajiaLan, MD reported in their study with nose being the most common location, ${ }^{15,21}$ while a cross-sectional study conducted by P. Lin manifested similar results to our study. ${ }^{24}$ As facemask encloses both nose and mouth it elevates the facial temperature emanating in discomfort. ${ }^{23}$ This may also be due to a variation in their skin type: $62.1 \%$ of the HCWs with oily skin developed acne, demonstrating a strong relationship between maskne and oily skin type. Despite conducting a thorough literature review, we could not find such an association to the best of our knowledge. However, research conducted by Anna Hwee Sing Heng proved this relationship. ${ }^{25}$ 


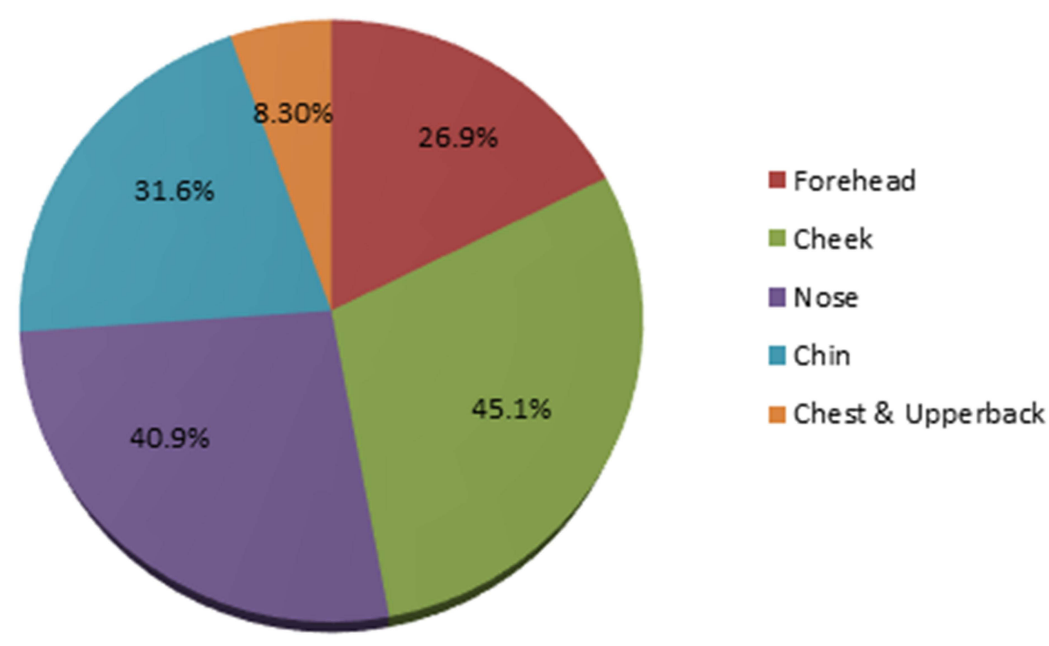

Figure I Distribution of acne.

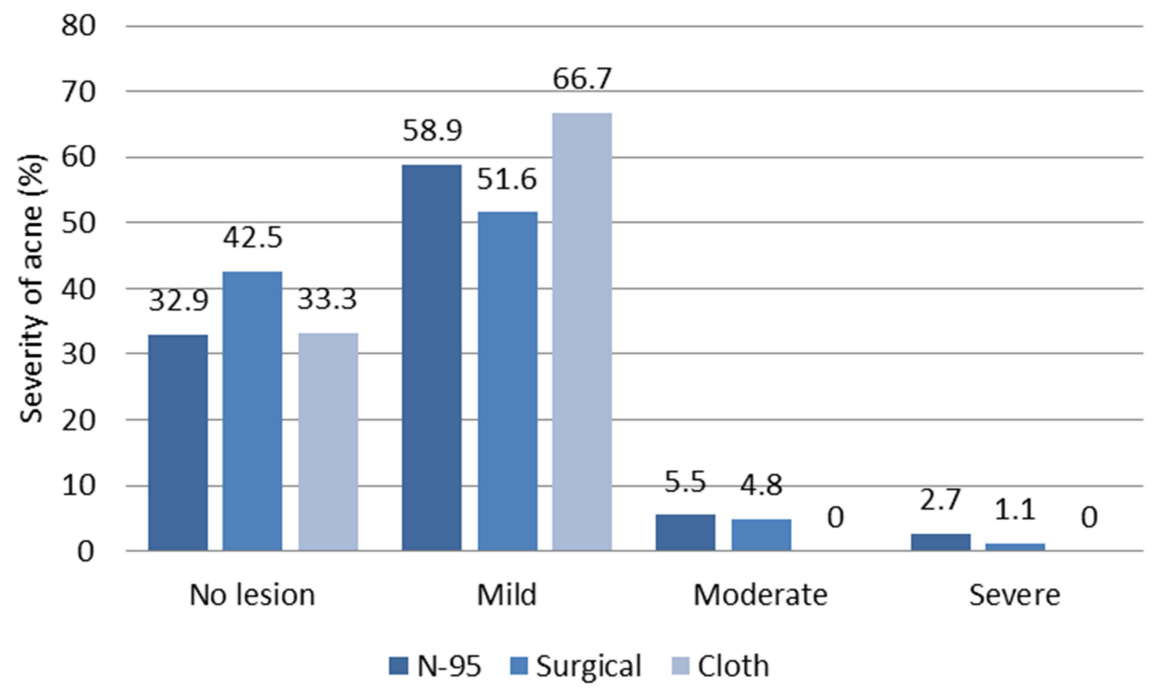

Figure 2 Severity of acne according to mask type.

The majority of healthcare workers had mild acne, which was frequently reported among cloth mask wearers. Those wearing surgical and N-95 masks, on the other hand, developed severe acne. This is consistent with what Chaiyabutr et al stated in their study. ${ }^{26}$ Surgical masks are typically made of multiple layers of fabric with two filter sheets, which may account for the severity. Furthermore, the thickness of N-95 with metal wiring covering the nasal bridge makes it more compact and airtight, resulting in a humid environment for bacterial growth and thus increasing severity. Cloth masks, on the other hand, are made of various textile materials, such as cotton, and provide comfort to the wearer. This result could also be attributed to the fact that the number of cloth mask users in our study was lower than the other groups. We were unable to trace any literature that established a link between face masks and acne amid COVID-19 pandemic.

\section{Limitations}

The site, sign and severity of the acne were all intuitive and not assessed by any dermatologist. Moreover, sample size of 193 is insufficient to project results on masses. In addition, certain elements such as stress and hormonal variation were not taken into consideration before deriving the conclusion.

\section{Conclusion}

Our study provides evidence of acne eruption after the use of face mask and discernment regarding its use. It further establishes an association of skin type with mask. Such details may 
help in finding effective interventions in order to reduce the possibility of acne onset. Understanding the guidelines and indications of World Health Organization (WHO) regarding proper use of mask, encouraging awareness among HCW and following proper doffing and donning protocol as endorsed by $\mathrm{CDC}$ can possibly minimize the adverse reactions. ${ }^{27}$ Additionally, the American Academy of Dermatology Association recommends 15-minute mask breaks every four hours, the use of moisturiser after face washing, the use of non-comedogenic beauty products, makeup-free skin, and the selection of an appropriate mask type. ${ }^{28}$

\section{Abbreviations}

HCW, healthcare workers; WHO, World Health Organization; GAGS, global acne grading system.

\section{Disclosure}

The authors report no conflicts of interest in this work.

\section{References}

1. Masood S, Tabassum S, Naveed S, Jalil P. COVID-19 pandemic \& skin care guidelines for health care professionals. Pak J Med Sci. 2020;36(COVID19-S4). doi:10.12669/pjms.36.COVID19-S4.2748

2. Das A, Kumar S, Sil A, Jafferaany M. Skin changes attributed to protective measures against COVID-19: a compilation. Dermatol Ther. 2020;33. doi:10.1111/dth.13796

3. Patruno C, Fabbrocini G, Stingeni L, Napolitano M. The role of occupational dermatology in the COVID-19 outbreak. Contact Dermatitis. 2020;83:174-175. doi:10.1111/cod.13568

4. Techasatian L, Lebsing S, Uppala R, et al. The effects of the face mask on the skin underneath: a prospective survey during the COVID-19 pandemic. J Prim Care Community Health. 2020; 11:2150132720966167. doi:10.1177/2150132720966167

5. Inan Doğan E, Kaya F. Dermatological findings in patients admitting to dermatology clinic after using face masks during Covid-19 pandemia: a new health problem. Dermatol Ther. 2021;34(3):e14934. doi:10.1111/dth.14934

6. Zhang B, Zhai R, Ma L. 2019 novel coronavirus disease epidemic: skin protection for healthcare workers must not be ignored. $J$ Eur Acad Dermatol Venereol. 2020;34(9):e434-e435. doi:10.1111/jdv.16573

7. Acne - Symptoms and causes. Mayo Clinic. Accessed October 1, 2021. Available from: https://www.mayoclinic.org/diseases-conditions/acne/ symptoms-causes/syc-20368047. Accessed October 01, 2021.

8. Markovic M, Soldatovic I, Bjekic M, Sipetic-Grujicic S. Adolescents' self perceived acne-related beliefs: from myth to science. An Bras Dermatol. 2019;94(6):684-690. doi:10.1016/j.abd.2019.02.005

9. Rudd E, Walsh S. Mask related acne ("Maskne") and other facial dermatoses. BMJ. 2021;373:n1304. doi:10.1136/bmj.n1304

10. Kosasih LP. Maskne: mask-induced acne flare during coronavirus disease-19. What is it and how to manage it? Open Access Maced J Med Sci. 2020;8(T1):411-415. doi:10.3889/oamjms.2020.5388

11. Daye M, Cihan FG, Durduran Y. Evaluation of skin problems and dermatology life quality index in health care workers who use personal protection measures during COVID-19 pandemic. Dermatol Ther. 2020;33(6):e14346. doi:10.1111/dth.14346
12. Han C, Shi J, Chen Y, Zhang Z. Increased flare of acne caused by long-time mask wearing during COVID-19 pandemic among general population. Dermatol Ther. 2020. doi:10.1111/dth.13704

13. Al Badri FM. Surgical mask contact dermatitis and epidemiology of contact dermatitis in healthcare workers: allergies in the workplace. Curr Allergy Clin Immunol. 2017;30(3):183-188.

14. Zuo Y, Hua W, Luo Y, Li L. Skin reactions of N95 masks and medial masks among health-care personnel: a self-report questionnaire survey in China. Contact Dermatitis. 2020;83:145-147. doi:10.1111/ cod. 13555

15. Lan J, Song Z, Miao X, et al. Skin damage among health care workers managing coronavirus disease-2019. J Am Acad Dermatol. 2020;82(5):1215-1216. doi:10.1016/j.jaad.2020.03.014

16. Kutlu Ö, Metin A. Relative changes in the pattern of diseases presenting in dermatology outpatient clinic in the era of the COVID-19 pandemic. Dermatol Ther. 2020;33(6):e14096. doi:10.1111/dth.14096

17. Donnarumma M, Nocerino M, Lauro W, Annunziata MC, Marasca C, Fabbrocini G. Isotretinoin in acne treatment during the coronavirus disease 2019 (COVID-19): a retrospective analysis of adherence to therapy and side effects. Dermatol Ther. 2021;34(1):e14677. doi: $10.1111 /$ dth. 14677

18. Gundogdu M, Dere G. Is systemic isotretinoin use a risk factor for coronavirus disease 2019 (COVID-19)? J Cosmet Dermatol. 2021;20 (6):1568-1570. doi:10.1111/jocd.14044

19. Doshi A, Zaheer A, Stiller MJ. A comparison of current acne grading systems and proposal of a novel system. Int J Dermatol. 1997;36 (6):416-418. doi:10.1046/j.1365-4362.1997.00099.x

20. Malik LM, Ilyas S, Hayat W, Mukhtar R, Rashid S, Rashid T. Skin manifestations associated with Personal Protective Equipment (PPE) in health care professionals during COVID 19 pandemic. Esculapio. 2020;16:61-65.

21. Singh M, Pawar M, Bothra A, et al. Personal protective equipment induced facial dermatoses in healthcare workers managing Coronavirus disease 2019. J Eur Acad Dermatol Venereol. 2020;34 (8):e378-e380. doi:10.1111/jdv.16628

22. Foo CC, Goon AT, Leow YH, Goh CL. Adverse skin reactions to personal protective equipment against severe acute respiratory syndrome-a descriptive study in Singapore. Contact Dermatitis. 2006;55 (5):291-294. doi:10.1111/j.1600-0536.2006.00953.x

23. Purushothaman PK, Priyangha E, Vaidhyswaran R. Effects of prolonged use of facemask on healthcare workers in tertiary care hospital during COVID-19 pandemic [published online ahead of print, 2020 Sep 15]. Indian $J$ Otolaryngol Head Neck Surg. 2020;1-7. doi:10.1007/s12070-020-02124-0

24. Lin P, Zhu S, Huang Y, et al. Adverse skin reactions among healthcare workers during the coronavirus disease 2019 outbreak: a survey in Wuhan and its surrounding regions. Br J Dermatol. 2020;183 (1):190-192. doi:10.1111/bjd.19089

25. Heng AHS, Chew FT. Systematic review of the epidemiology of acne vulgaris. Sci Rep. 2020;10:5754. doi:10.1038/s41598-020-62715-3

26. Chaiyabutr C, Sukakul T, Pruksaeakanan C, Thumrongtharadol J, Boonchai W. Adverse skin reactions following different types of mask usage during the COVID-19 pandemic. J Eur Acad Dermatol Venereol. 2021;35(3):e176-e178. doi:10.1111/jdv.17039

27. CDC. Covid-19 and your health. Centers for disease control and prevention; February 11, 2020. Available from: https://www.cdc. gov/coronavirus/2019-ncov/prevent-getting-sick/about-facecoverings.html. Accessed September 19, 2021.

28. 9 ways to prevent face mask skin problems. Available from: https:// www.aad.org/public/everyday-care/skin-care-secrets/face/preventface-mask-skin-problems. Accessed September 19, 2021. 


\section{Publish your work in this journal}

Clinical, Cosmetic and Investigational Dermatology is an international, peer-reviewed, open access, online journal that focuses on the latest clinical and experimental research in all aspects of skin disease and cosmetic interventions. This journal is indexed on CAS.

The manuscript management system is completely online and includes a very quick and fair peer-review system, which is all easy to use. Visit http://www.dovepress.com/testimonials.php to read real quotes from published authors.

Submit your manuscript here: https://www.dovepress.com/clinical-cosmetic-and-investigational-dermatology-journal 